\title{
RELACIONAMENTO AMOROSO CONJUGAL DURADOURO NA CONTEMPORANEIDADE: UMA ANÁLISE FENOMENOLÓGICA DE VIVÊNCIAS
}

\author{
Long-lasting conjugal love relationships in the contemporaneity: \\ a phenomenological analysis of experiences
}

Relacionamiento amoroso conyugal duradero en la contemporaneidad: un análisis fenomenológico de vivencias

\begin{abstract}
Resumo: O objetivo central deste trabalho foi investigar como se configura a estrutura da experiência de relacionamentos amorosos conjugais duradouros na contemporaneidade. Para empreender o estudo, foi feita uma pesquisa de campo na região da Grande Belo Horizonte junto a pessoas que vivem essa modalidade de relacionamento, selecionadas a partir de critérios objetivos (amostra intencional). Para a coleta de dados, foram realizadas entrevistas semiestruturadas e de caráter não diretivo, no intuito de preservar o dinamismo característico da experiência. Foram expostos os trechos das entrevistas previamente gravadas e transcritas, que revelavam mais claramente o fenômeno investigado. A análise fenomenológica se fez presente nesse momento e contribuiu para o alcance de unidades de sentido que, em seguida, foram discutidas amplamente, após serem sintetizadas em dois eixos: 1) a experiência do amor conjugal duradouro enquanto desprovida do romântico; 2) a experiência do amor conjugal duradouro como abertura. Sendo assim, na análise do modo como os sujeitos elaboram sua experiência, compreendeu-se a sua estrutura como integradora de amor desromantizado e abertura.
\end{abstract}

Palavras-chave: Fenomenologia; Amor; Conjugalidade; Duradouro; Contemporaneidade.

\begin{abstract}
The main objective of this study was to investigate how the structure of the experience of long-lasting conjugal love relationships is configured. To accomplish this endeavor, field research was conducted in the Greater Belo Horizonte area with people selected through objective criteria (intentional sample), who experience the referred relationship model. For the data collection, non-directive and semi-structured interviews were conducted in order to preserve the dynamics of the experience. Excerpts from previously recorded and transcribed interviews, which more clearly revealed the phenomenon investigated, were exposed. The phenomenological analysis was used at this moment and contributed to the achievement of meaningful units, which were discussed more broadly after being synthetized in two axes: 1) the experience of long-lasting conjugal love as deprived of romanticism; 2) the experience of long-lasting conjugal love as openness. Therefore, in the analysis of how the subjects elaborate their experience, it was possible to understand the structure as integrating non-romantic love and openness.
\end{abstract}

Keywords: Phenomenology; Love; Conjugality; Long-lasting experience; Contemporaneity.

Resumen: El objetivo central de este trabajo fue investigar cómo se configura la estructura de la experiencia de relacionamientos amorosos conyugales duraderos en la contemporaneidad. Para emprender el estudio, fue hecha una investigación de campo en la región del Gran Belo Horizonte junto a personas que viven esta modalidad de relacionamiento, seleccionadas a partir de criterios objetivos (muestra intencional). Para la recolección de datos, fueron realizadas entrevistas semiestructuradas y de carácter no directivo, con la intención de preservar el dinamismo característico de la experiencia. Fueron expuestos los fragmentos de las entrevistas previamente grabadas y transcritas, que revelaban más claramente el fenómeno investigado. El análisis fenomenológico se hizo presente en este momento y contribuyó para alcanzar unidades de sentido, que enseguida fueron discutidas ampliamente después de haber sido sintetizadas en dos ejes: 1) la experiencia del amor conyugal duradero como carente de romántico; 2) la experiencia del amor conyugal duradero como apertura. Por consiguiente, en el análisis de la forma como los sujetos elaboran su experiencia, se entendió su estructura como integradora de amor desromantizado y apertura.

Palabras-clave: Fenomenología; Amor; Conyugalidad; Duradero; Contemporaneidad.

\section{Introdução}

Diante da multiplicidade de eixos e áreas envolvidas no estudo do amor, há variadas complicações na abordagem do tema, que, em seus excessos, despejam incontáveis inferências capazes de gerar confusão e desorientação ou, por vezes, são insufi- cientes na tentativa de compreendê-lo. Quanto ao empreendimento de tomar a investigação de uma de suas manifestações, o amor conjugal, a situação ainda se torna mais difícil, especialmente com a inserção do qualificativo "duradouro", que afunila o campo e levanta curiosidades estimulantes ao debruce.

Busca-se embasamento e orientação deste trabalho a partir da elucidação de conceitos vitais. $\mathrm{O}$ 
conteúdo abrange, dessa forma, um aporte teórico-metodológico da Fenomenologia/Análise Fenomenológica (Ales Bello, 2004, 2006; Amatuzzi, 1996, 2009; Husserl, 1952/2006a; Stein, 2003; van der Leeuw, 1933/1964), aproximação escolhida para se dirigir ao investigado. Isto significa entender que a discussão adquire um intuito de compreender a experiência de amor conjugal duradouro do ponto de vista da pessoa que a vive.

O objetivo geral foi investigar como se configura a estrutura da experiência de relacionamentos amorosos conjugais duradouros na contemporaneidade. Ainda que exemplificativo do momento atual, este termo carece de especificidades que permitem uma caracterização mais detalhada de um perfil de indivíduo específico desta época. Por este motivo, encontra-se na literatura sociológica atual, possibilidades de se compreender o retrato do indivíduo do agora através dos aportes dos proponentes

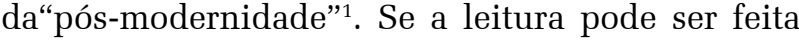
a partir dessa ótica, em que se está diante de uma objetalização das relações, uma exacerbação de prazeres imediatos, de fenômenos relacionais efêmeros e líquidos, onde se nota uma fragilização e um afrouxamento de laços na contemporaneidade (Bauman, 2004, 2007, 2008; Lipovetsky, 1989, $2004,1987 / 2009$ ), por que algumas pessoas permanecem em relações amorosas conjugais se há uma legitimação da desnecessidade de permanência? $O$ que torna o duradouro possível?

\section{Referencial teórico-metodológico e procedimentos da pesquisa}

\section{Fenomenologia, subjetividade e intersubjetividade}

A fenomenologia evita dicotomias quando o assunto é subjetividade, pois articula sujeito e objeto como elementos de uma mesma raiz. Dirige um olhar para o que brilha, o fenômeno, na observação ativa de sua manifestação e na investida de sua compreensão (Ales Bello, 2004, 2006). Ela permite um entendimento da relação entre pessoa e mundo através da análise da realidade enquanto percebida por alguém, ou, nas palavras de Amatuzzi (2008): "Não é o mundo em si, mas o mundo tal como experienciado pelo homem". (p. 48). É tomando as vivências e a vida da consciência como parâmetro que se almeja uma compreensão do mundo do sujeito e do contexto cultural, que é profundamente alcançado pela investigação da subjetividade e, consequentemente, da intersubjetividade.

A vida humana acontece em um contexto com outros humanos. Nesse sentido, pode-se dizer de um nós, pois o mundo é comum, e todos vivem, compartilham e interpretam esse espaço (Ales Bello, 2006). Todo o processo se dá pelo reconhecimento da alteridade, na medida em que o olhar

\footnotetext{
1 Embora o contexto atual seja muito referido como "contemporaneidade", recebe inúmeros nomes, interpretações e leituras advindos de pontos de vistas distintos de autores diversos. Entre as várias concepções, estão a de "pós-modernidade" ou "modernidade líquida", do sociólogo polonês Zygmunt Bauman, e a de "hipermodernidade", do filósofo francês Gilles Lipovetsky.
}

do outro convida a pessoa a olhar para si mesma e se posicionar. O protótipo de todo relacionamento social é uma conexão intersubjetiva de motivos. Entender o mundo por meio de suas próprias experiências e compreender o outro implica a explicação das experiências individuais vividas em relação, e tal processo de apreensão ocorre em um "espaço" compartilhado. Amatuzzi (2009) diz que "o contexto da experiência é interpessoal: nascemos em um grupo humano e vivemos junto a outros.” (p. 96). Sendo assim, a maneira fenomenológica de pensar considera o encontro das subjetividades.

Outro aspecto a ser salientado são os subsídios trazidos pela fenomenologia para a definição de pessoa, os quais guarnecem fundamentos para a compreensão de uma estrutura comum humana. Por sua vez, as vivências têm particularidades que delimitam pontos reveladores do ser humano e se configuram como bases da subjetividade, (Husserl, 1952/2006a; Ales Bello, 2004). Tais pontos são constituídos por três dimensões básicas: corpórea, psíquica e espiritual. ${ }^{2}$ Diante disso, o entendimento da subjetividade estende-se a uma proposta antropológica que vai desde a diferenciação das qualidades de vivência até a legitimação de dimensões distintas do humano.

Subjetividade, intersubjetividade e mundo, portanto, são discutidos todo o tempo conforme acontece o trânsito entre o pessoal, o interpessoal e a cultura, que assume significado mais ativo e vivo, contrariamente a um produto acabado (Amatuzzi, 2008).

A obra de Buber (1923/2015) dialoga com a leitura fenomenológica de maneira mais próxima quando oferece consistência para se resgatar a pessoa dentro de um espaço inter-humano, a partir do conceito de "relação dialógica", no sentido de abertura ao outro. É necessário que esta relação e o contato com a alteridade provoquem o contato com a própria experiência e solicitem um nível de resposta mais profundo, pois só é possível vincular-se quando o outro, ao invés de ser mero objeto, passa a ganhar efetiva importância para a vida da pessoa que a ele se une (Buber, 1923/2015; Stein, 2003).

\section{Análise fenomenológica e procedimentos metodológicos}

A maioria das abordagens do tema se dedica a análises históricas, antropológicas e sociológicas, de modo que é notável uma necessidade de se lançar um olhar ao amor do ponto de vista da experiência da pessoa. O trabalho se centrou na volta aos dados primordiais da experiência (Andrade e Holanda, 2010), deflagrada na relação interpessoal e intersubjetiva entre os sujeitos. Barreira e Raniere (2013) dizem que a entrevista fenomenológica tem uma maneira própria de funcionamento por não partir de teorias prévias para se aproximar dos fenômenos.

Para evitar desvios, o trabalho utilizou de amostragem intencional. Dedicou-se a encontrar

2 Vale advertir que a palavra espirito em nada se relaciona com religiosidade ou "entidade superior". 
pessoas representativas do recorte da investigação: aquelas que declaravam que estavam em relação, que havia amor na relação e que consideravam viver relações amorosas conjugais duradouras. Foram buscados relacionamentos de longevidades diferentes e, apesar de o trabalho contemplar uma amostra pequena, tentou-se, ainda assim, formá-la com alguma diversidade, pois como afirmam Gaspar e Mahfoud (2010), "quanto mais explicitamos diferenças existentes entre um sujeito e outro, mais podemos apreender com certeza e rigor a estrutura da experiência investigada”. (p. 5).

A escolha do local deixou-se a critério dos próprios entrevistados. No caso de incômodo pela falta de privacidade da própria residência ou dos espaços conhecidos, disponibilizou-se um espaço alternativo. O Centro de Psicologia Humanista (CPHMINAS), uma instituição sem fins lucrativos que funciona atualmente em uma casa localizada no bairro Prado, em Belo Horizonte, possui uma estrutura com salas de atendimento que muito se adequam a situações de entrevista, por serem privativas e aconchegantes.

Realizaram-se oito entrevistas de caráter semiestruturado, gravadas em áudio, preservando-se as características próprias dos depoimentos de cada um dos entrevistados, no intuito de capturar o maior quilate da cena, para privilegiar o vivido. Optou-se pela transcrição de três das entrevistas, acreditando que, por sua riqueza, pudessem revelar elementos mais expressivos. Foram levados em consideração o grau de aprofundamento e a qualidade da descrição da experiência, haja vista que são requisitos para uma boa análise a partir dessa metodologia.

As entrevistas fenomenológicas tiveram como ponto de partida uma pergunta norteadora do processo, voltada aos objetivos da pesquisa, ao mesmo tempo não denunciadora do problema central: “como é estar com (...) há (...) anos?”. Foi utilizado o critério característico de condução não diretiva, de modo a alcançar um nível de profundidade satisfatório, como expressam Smith e Eatough (2010). O foco não é no material concreto ou nas informações genéricas (Amatuzzi, 1996), nem na opinião dos entrevistados, mas na expressão da experiência que subjaz à fala, pois “o depoimento não é sempre a manifestação direta e imediata do vivido em questão”. (Amatuzzi, 2008, p. 59). Sendo assim, os entrevistados puderam transitar por onde encontraram mais sentido, o que assegurou um aprofundamento e genuinidade dos achados. O estudo preocupou-se com o objetivo de manter o relato espontâneo, o que não é o mesmo que tê-lo arbitrariamente (Barreira \& Ranieri, 2013).

Em seguida, os dados foram trabalhados sob a luz da análise fenomenológica, que investiga a organização e a manifestação das vivências (Amatuzzi, 1996; Ales Bello, 2004). A epochè, atitude crítica de suspensão de juízos, crenças e conhecimento teórico prévio (Ales Bello, 2004; Garnica, 1997; van der Leeuw, 1933/1964), foi condição para a modalidade de análise escolhida, objetivando captar fragmentos essenciais constituintes do fenômeno. Tal atitude evita a sobreposição de categorias de sentido sobre o fenômeno investigado e é uma tentativa clara de descontaminar o conhecimento sobre o objeto (Gaspar \&Mahfoud, 2010), por vezes carregado de pré-conceitos. A epochè, facilitando uma mudança que abandona a atitude natural - quando se passa a ver o mundo do sujeito como fenômeno -, abre espaço para a "redução fenomenológica" (Andrade \& Holanda, 2010, p. 262), que pode ser entendida como o recurso que propicia a aproximação da essência, ou seja, aquilo que é verdadeiramente inerente ao fenômeno.

O trabalho seguiu os passos metodológicos propostos por van der Leeuw (1933/1964): (1) leitura atenta e repetida das transcrições das entrevistas; (2) releitura, tendo como eixo a vivência consciente e a atenção às ressonâncias provocadas no pesquisador; (3) suspensão de convicções pessoais para a apreensão do sentido; (4) estabelecimento de categorias iniciais em que se buscará ressaltar as conexões de sentido existentes; (5) vivência de compreensão do fenômeno e correção continuada das análises por meio do retorno ao depoimento e ao que foi suspenso; (6) exame das compreensões alcançadas em espaços coletivos e confronto com o referencial teórico-metodológico adotado; (7) reconstrução da experiência vivida pelo sujeito e formalização da experiência-tipo ${ }^{3}$ para acessar a compreensão da vivência.

Apoiado na fenomenologia enquanto referencial teórico, entende-se que os âmbitos particulares da experiência (normalmente mais superficiais ou explícitos) provocam a emergência dos âmbitos específicos a ela. Identifica-se o ponto de saturação de dados no momento em que algumas informações obtidas no campo começam a repetir-se insistentemente, em direção a uma redundância. Para a fenomenologia, não se trata de uma repetição por incidência de palavras, mas sim em relação ao retorno às unidades de sentido, as quais, ao serem analisadas, apontam para uma especificidade.

\section{Apresentação dos resultados}

Maria Rita: "é difícil"

Em uma agradável manhã de sol brando, "Maria Rita”, ${ }^{4}$ uma senhora católica, se encontrava na janela de casa a contemplar o movimento da rua à espera da minha chegada. Com um vigor invejável para uma franzina mulher de 87 anos, ela veio, a passos curtos e firmes, portando a penca de chaves e um olhar vexado. Fui conduzido até a sala de estar, onde nos acomodamos um de frente para o outro, sentado eu no sofá e ela, em uma poltrona.

Estava visivelmente acanhada com a situação de entrevista, mas o estranhamento se confirmou

\footnotetext{
3 Esta se refere exatamente a uma estrutura encontrada a partir dos sentidos que se abrem aos sujeitos em suas experiências (van der Leeuw, 1933/1964).

4 Todos os entrevistados e as demais personagens presentes nas histórias narradas receberam nomes fictícios, segundo Termo de Consentimento Livre e Esclarecido.
} 
passageiro, pois, mediante o início da conversa, uma certa tensão esvaiu-se. "É difícil" - ecoou a voz aguda e delicada em resposta à pergunta sobre como é viver há 67 anos em relação com "Seu Emanuel" (marido).

"Ser difícil" foi um termo usado no início e permaneceu recorrente no depoimento. E não só o difícil como conectado ao relacionamento, mas também às próprias vidas. Elas aconteceram muito tempo juntas, e isso é o que a entrevistada mostra no início da entrevista quando seu marido tratou de toda a família em alguns momentos. Eles já estavam juntos. Algo sob a dificuldade da situação familiar do marido ilumina os caminhos de uma admiração de Maria Rita por Seu Emanuel.

$\mathrm{O}$ assunto segue com fluidez para questões ligadas ao tato cotidiano entre os cônjuges. Maria Rita explica sobre situações de discórdia, apresentando um funcionamento específico do casal:

Às vezes, um respondia [brigando] e [o outro] não respondia. Aí ficava calado, fechava a boca né... [Porque] se continuar, ia pra frente, né. (...) E foi indo assim (risos). Na mesma hora tava tudo do mesmo jeito, graças a Deus, viu. (...) Ô.... ele nunca falou comigo: "Você não vai sair!” (...) Ele nunca falou assim...

Parece que os cônjuges encontraram mecanismos próprios e particulares de manutenção da relação. E é disso que ela trata anteriormente, após ter expressado a admiração pelo marido. A mulher diz que quando um "respondia" (no sentido agressivo da discussão), o outro "ficava calado". Ou seja, havia uma vontade ou um dever de não contrariar. Ela complementa associando essa forma de relacionar como peça chave para uma permanência juntos: "e foi indo assim”. Essa maneira própria de administrar conflitos aparenta ser um tipo de sabedoria prática que está conectada a uma postura de tolerância. De outra parte, certo respeito ou permissividade são similarmente identificados quando ela afirma que nunca sofreu de proibições do marido.

A história é permeada por dificuldades narradas. Repetidas são as vezes em que a entrevistada dá o testemunho de solavancos resultantes do árduo cenário da vida que levaram. Quando entra profundamente nos obstáculos vividos, ela compartilha:

Era sofrimento desde menina e depois que casou também. É uai, sem dinheiro. Essa construção aqui é Deus, porque não tinha dinheiro, era o que ele ganhava. (...) Deus mandou a empresa, lá eles mandaram embora e Deus ajudou que a gente veio pra cá. De noite, de manhã, e de madrugada, de sábado e domingo a gente fazia o alicerce aqui. (...) Eu, Deus e ele

\footnotetext{
5 De forma a preservar a máxima fidedignidade dos depoimentos colhidos, a transcrição da oralidade não sofreu revisão gramatical. As intervenções se restringem ao acréscimo de elementos em parênteses - para marca ênfase na fala dos entrevistados, reações como riso etc. - e em colchetes - para apontar conectivos e outras palavras omitidas das falas (elipses), cuja ausência, na transcrição, poderia comprometer a apreensão do sentido por parte do leitor.
}

que fez o alicerce aqui dessa casa. (...) Hoje em dia ninguém sabe o que é sofrimento não, (...) eu falo, eles nasceram em berço de ouro e não sabe, não sabe o que tá falando ainda, viu.

O aprofundamento na dita "dificuldade", tão enfatizada, acontece na rememoração de situações fastidiosas vividas pelo casal. Ausência de dinheiro, perda de emprego do marido, dificuldade de moradia, o trabalho na construção da casa, sem muita ajuda. Maria Rita ergueu a própria casa, tijolo por tijolo, junto com o marido. Ela apela a Deus, enquanto a principal razão da superação de todos os desafios, mas não deixa de reconhecer o trio: "eu, Deus e ele", sugerindo que, além do poder divino, o próprio casal era o único suporte, e que eles (Maria Rita, Emanuel e Deus) foram os responsáveis pela construção de tudo. Nada obstante, delineia-se uma cumplicidade e um companheirismo, que se anunciam como parte de uma vivência do acompanhar um ao outro, do apoiar, às vezes por meio da simples presença nas situações corriqueiras que a vida presenteia. A camaradagem que permeia a convivência denota o entendimento dos dois, um ao lado do outro.

O final da fala revela como reconhece o tamanho de seu sofrimento, uma vez que crê ser inigualável ao sofrimento das pessoas atualmente: "hoje em dia ninguém sabe o que é sofrimento não”. A partir da análise dessa passagem, Maria Rita relata acreditar que conhece o sofrimento como ninguém, até porque são inúmeras as vivências de dor junto ao marido.

Um acontecido recente de semelhante sofrimento teria sido um acidente com Seu Emanuel. Ele exerce, até hoje, com mais de 90 anos, o ofício de marceneiro, mantendo sua oficina de trabalho no porão da casa. Muito provavelmente por causa da idade (já não bastasse o risco inerente ao trabalho), ele perdeu há alguns meses um dedo na serra de corte de madeira. Infelizmente, esse não foi seu primeiro acidente. A entrevistada conta sobre como foi a situação:

Muito difícil, viu. (...) Tinha que por comida na boca dele! Um dia, uma conhecida (...) veio com o marido dela, né. (...) Eu fiquei sem jeito de dar ele o café, e sem jeito de não dar o café. Aí eu peguei e fui molhando o pão, o biscoito na boca dele e ia com o café. Aí o casal chegou em casa e falou assim: "ó, se eu precisar você faz comigo assim, igual ela fez?’ Aí o outro respondeu assim: "e se eu precisar, você faz?" E ficou por isso mesmo (risos). (...) Aquelas máquinas são perigosas; três máquinas. Todo mundo quer que ele pare. (...) Alá, máquina tá ligada (barulho de máquina ao fundo).(...) É perigoso sim, na hora que as máquinas começam a rodar você precisa de ver, ninguém vê elas rodarem não.

Maria Rita deu comida na boca de Seu Emanuel. Fragilizado e incapacitado, ele precisava de cuidado. A franzina senhora deixa escapulir um estranhamento ou constrangimento de fazê-lo, es- 
pecialmente na frente de outras pessoas. Em seguida, manifesta orgulho, ao perceber que seu gesto foi legitimado e apreciado pelo casal que visitava. Ela ri da situação, claramente satisfeita. Pode ser que o gesto - de dar comida na boca de seu marido lhe parecesse uma grande exibição de intimidade, e que justamente esse fato provocasse um recato de sua parte. Contudo, o prazer do reconhecimento recebido sobrepôs-se ao desconforto.

A despeito de seu cuidado, também a preocupação fez aflorar o amor pelo marido. A mulher apresenta ciência sobre os riscos de se trabalhar com as serras, já que "ninguém vê elas rodarem". Ademais, quando afirma que "todo mundo quer que ele pare”, ela não se deixa de fora, dirigindo a mão ao peito. Tanto cuidado como preocupação aparecem juntos nesse instante da entrevista.

De uma forma geral, as adversidades enredam uma história comovente, saturada de eventos penosos e de condições desgastantes pelas quais, a duras custas, passou o casal. Tendo viva para si a condição de dificuldade que permeou sua vida com o esposo, Maria Rita tem também consciência de que desfrutou de bons momentos. Ela pontua, ao fim da entrevista, que ainda que a construção da casa fosse tanto uma prioridade quanto uma urgência, havia a chance de criar e aproveitar momentos de entretenimento e de descanso, afinal "não pode ser só trabalhar também não”.

Por um breve momento, a impressão é de que ela tenta "atenuar" a qualidade do sofrimento. Porém, constata-se que esse intento é uma organização interna para lhe ceder uma justificativa - de que podia se sentir bem -, pois já está muito claro que havia grande sofrimento. Sendo assim, a conclusão que parece apropriada não é de que ela queria abrandar o que de negativo lhe sucedia, mas de que o fazia enquanto solução para que pudesse usufruir do prazer, que também era vivido.

\section{Polyanna: sacrifício em nome do transcendente}

Para um primeiro contato, Polyanna pareceu relativamente tranquila. Sentada perto à beira do sofá, repousando os cotovelos sobre os joelhos e cabeça sobre as palmas das mãos, Polyanna inicia o relato de sua história de nove anos de relacionamento, deixando vagar o olhar em busca do contato com a experiência.

Ela atravessa um primeiro instante onde compartilha como foi se descobrir homossexual e como foi a surpresa dessa descoberta. Assim, inaugura o assunto da relação atual, a qual não se deu por vias da paixão, mas que representou grande impacto, pois o vivido foi algo como um sentimento inédito-mágico. Ela mesma explica que "mágico" é apenas uma palavra para ajudar a descrição, para torná-la fácil, mas o que realmente deveria ser dito está além das palavras.

Em seguida, ela se dirige a um momento distinto, deixando de falar sobre o estabelecimento da relação em questão e entrando progressivamente na esfera de sua intimidade conjugal. Polyanna se sente emocionada ao contar:

Aí a gente começou até assim... ir em tipo Canção Nova, sabe? (...) E a gente começou a ouvir umas palestras, umas coisas, e lá aconteceu uma coisa com ela [Lurdinha, a companheira](...) ela falou assim: "ah, tive a impressão que... o Cristo tava caminhando aqui” (voz engasgada, choro). Aí (...) teve um momento lá, que ela sentiu, como se ela tivesse (...) tomado um choque... que fosse no seu corpo todo (...) E aí, ela me contou isso quando a gente chegou em casa e tal.... (...) a gente até chorou (chora bastante, pausa longa) (...) Aí nós conversamos e falamos assim: vamos fazer um negócio então? (emocionada, com fala meio descontrolada) A gente vai é... abrir mão, né (engasgada), (...) a gente vai parar de ter o relacionamento sexual. Aí ainda falei assim: "mas nós não vamos parar de beijar nem nada não, e tal, porque aí também é demais".

Lurdinha teve um potente contato com o transcendente; uma revelação. Polyanna, por sua vez, partilha com a companheira a vivência, comove-se, demonstrando enorme cumplicidade. A troca envolveu um diálogo, um compartilhamento e uma decisão sobre o ocorrido, tendo Polyanna valorizado a importância do fato e da vivência de Lurdinha.

$\mathrm{O}$ evento instaurou um drama e um dilema que não era esperado, instigando naturalmente uma negociação. Explícita a necessidade de Lurdinha, Polyanna reivindicou: "mas nós não vamos parar de beijar (...) porque aí também é demais”. O confronto, em seu significado de convocação à presença, ao posicionamento e à produção de sentido da relação, sucede.

Percebe-se o quanto ter que abrir mão da parte sexual da vida conjugal representou um esforço ou um preço alto pago "por um amor maior". Houve, por fim, um consentimento quanto a essa abnegação, o que fez emergir uma experiência de renúncia, que não se conecta apenas ao pacto de abstinência do sexo, mas, sobretudo, se refere à experiência de Polyanna quando esta abre mão de seus desejos e vontades por Lurdinha (que trouxe a proposta inicial). A renúncia, portanto, significou um esforço sofrido que implicou privação e abstinência, ou seja, um sacrifício pela necessidade da parceira. Por seu amor e companheirismo e na tentativa de favorecer a continuidade da relação, Polyanna consentiu.

À parte o amor religioso, que é um ponto central na relação, transborda também o amor conjugal. Fazer permanecer o amor ou alimentá-lo se unia à vontade de corresponder a essa expectativa, tão importantemente revelada. O gesto é uma explicitação de doação. De uma forma geral, independentemente da vontade de Polyanna de atender à demanda suscitada pela vivência de Lurdinha, o fato de tê-la tomado como fundamental no prosseguimento de sua própria relação demonstra a generosidade e o ímpeto de cuidar. O cuidado certamente se articula com a renúncia, o sacrifício e a doação. 
Com o passar do tempo, segundo a narração da entrevistada, as coisas também mudaram para ela. Soube-se que, anteriormente, a proposta de abstinência em devoção partia de Lurdinha, mas Polyanna esclarece:

Com o tempo, a gente foi conversando mais (...) e ficando mais religiosa, (...) aí nós entramos num acordo de novo, e paramos de beijar. $E$ vamos viver agora como amigas e tal, mas assim... a gente não vai deixar de dormir junto... não vai deixar de brincar. Então, a minha vida hoje com ela... é como se... (engole seco) a gente fosse... duas irmãs, entendeu? Mas é lógico que o carinho e o amor, ele continua, ele vai ser eterno, né... (...) Igual uma vez nós vimos uma moça dando uma entrevista na televisão, no estrangeiro, que ela dorme com rapazes, e tal. Os rapazes pagam a ela pra dormir de conchinha, porque ela tem aquele negócio ali... de atender as pessoas daquela forma e... (...) é comprovado que aquilo faz um efeito benéfico.

Ela também sofre uma transformação, quando se torna mais devota e religiosa. O envolvimento ocorre cada vez em maior grau de reciprocidade: em Polyanna e em Lurdinha crescem a renúncia e o sacrifício. Assegura nossa protagonista, no entanto, que o amor permanece e também o carinho, colocando em evidência um companheirismo. Esse "viver junto" não inclui mais vivências afetivo-sexuais, de modo que sugere uma mudança no amor conjugal das duas, ou pelo menos, na manifestação dele. Mas este amor "vai ser eterno" - isso é o que Polyanna crê. A entrevistada compara o que elas têm ao amor entre irmãs, por não visar à satisfação sexual nem realizá-la. Mas o que fica bastante característico é a necessidade de vivenciar formas particulares de realização emotivo-afetivas juntas. Sempre juntas.

O mais curioso da situação é que, no caso das duas amantes, há significativa diferença quando comparado à entrevista da televisão: ambas escolhem "dormir de conchinha" apenas uma com a outra e não com qualquer um(a). A opção segue sendo a de permanecer juntas. A vontade de dividir experiências e de compartilhar a dimensão afetivo-emocional aponta para apenas uma pessoa: Lurdinha. Polyanna não hesita quando diz o seguinte: “Com o passar do tempo, eu fui aprendendo a gostar mais (ênfase), a me apaixonar (ênfase)... e amar (ênfase), entendeu? Acredito sim que a paixão (...) não fica eternamente, mas o amor sim, entendeu?

Ela acrescenta à concepção trazida sobre o amor e aqui explica que ele é uma construção a prazo e que a convivência o edifica, assim como o fez na sua relação com Lurdinha. O momento "mágico", segundo sua lógica, haveria servido para provocar a escolha da parceira; contudo, a sustentação da relação seria realizada pelo assentamento do sentimento. Ela escolheu dar espaço ao amor em uma relação inicialmente banhada de paixão.

Novamente, muita emoção irrompe quando ela fala sobre as escolhas e a caminhada de sacrifícios:
Às vezes, a gente olha pela emoção... do que a gente fez, ou se faz ainda (choro, voz trêmula)... e fica uma (...) saudade [ênfase] de algo diferente (choro intenso), entendeu? (...) por mais que a gente (...) goste, né, de alguma coisa, a gente tem que tentar, entre aspas, é... seguir um certo... entendeu?

Polyanna sente muita nostalgia de momentos anteriores do relacionamento, quando talvez por não conhecer ainda o que conhece hoje, se sentia muito livre para usufruir da relação. Quando afirma que "por mais que a gente (...) goste (...) a gente tem que (...) seguir um certo", ela, em outras palavras, está dizendo que por mais que sinta algo que considere imoral, deve agir dentro do que para ela é uma moralidade e que representa um valor muito forte, o que pode ser bem entendido a partir da passagem a seguir:

Aí que veio essa questão dessa abstinência nossa e tal... (...) Eu sou feliz do jeito que eu tô hoje, e eu sou feliz na opção (engasgada) e no que nós fizemos, né, mas... (...) eu falo assim: "mas será que a gente nâo precisaria de mais coisa tipo, nem dormir junto (ênfase)... entendeu?" Pra ser um certo perfeito (engole seco). (...) Mas... eu sei que, acaba que, o amor, (controlando o choro) ele até aumentou, entendeu? (...) É legal como tudo isso que a gente fez, aumentou mais, fortaleceu mais, entendeu?

A entrevistada vive um grande dilema: funcionar segundo uma moral cristã, condenadora do sexo homossexual, vivendo o que crê ser o certo e em harmonia também com as crenças da parceira, ou atender seu desejo de estar mais próxima e desfrutar dos prazeres do sexo e de uma relação mais afetivo-sexual.

A partir de sua história, sabe-se que, atualmente, ela opta pela primeira opção, o que não exclui o autoquestionamento e alguma hesitação quando se flagra a si mesma em seu desejo. De outra parte, no momento que consuma qualquer ímpeto dessa ordem, escorrega sobre o solo da culpa, denunciando que o dilema é presente. O que se conclui é que a vontade de estar junto é maior, e Polyana afirma veementemente que o amor aumentou diante de toda essa tensão. Enfim, falar de amor por Lurdinha é falar igualmente do sacrifício que é lidar com seu desejo ou com a renúncia dele.

\section{Castanheira: as picuinhas do convívio}

O homem tem estatura mediana e olhar calmo; é relativamente calvo e usa óculos. Desde o princípio, tive a impressão de moderada ansiedade, porém a percepção acabou por revelar o brilho de uma imensa vontade de compartilhar sua história. Em poucos minutos, o que era ansiedade se converteu em entusiasmo. Sua narrativa é integralmente 
abundante em detalhes e envolvente em cada pequeno fragmento.

Castanheira é um policial recentemente reformado que vive mudanças provenientes da nova fase de vida. Ele inicia seu relato trazendo o impacto incipiente que afeta diretamente seu relacionamento conjugal:

É um baque muito grande... você passar 24 horas com uma pessoa, mesmo que você tenha um relacionamento duradouro com ela, mas ali você vai passar a ficar 24 horas com ela. Você acorda com ela e dorme com ela. Já era assim... Agora o que você vai fazer de trabalho em casa é com ela ao lado... Então começa, assim, umas picuinhas bobas... isso aí é fato (ênfase)... não tem jeito... entendeu?

Conta sobre essa reconfiguração, pois passa a conviver mais intensamente com a esposa, por estar em casa a maior parte do tempo, ao seu lado. Nesse sentido, os dois são confrontados todo o tempo com as presenças um do outro, e a convivência, segundo Castanheira, leva a "picuinhas", que podem ser entendidas como implicâncias. "Já era assim", ou seja, já havia, pode-se dizer, aborrecimentos naturais ao convívio, entretanto, agora este é tão mais intenso que gera essas amolações excessivas e inevitáveis "não tem jeito". Ele prossegue:

Ela é uma mulher muito assim... além de ser cuidadosa com tudo o que ela tem, ela é muito meticulosa, muito detalhista. (...)Porque inclusive até quando eu faço ela vem corrigindo.... Você fica naquela... eu estou fazendo um serviço que vai ser corrigido. Além de ser vigiado, vai ser corrigido. Então pra que eu vou fazer? Te desestimula.

O entrevistado avança, então, com uma descrição da esposa em sua forma de ser e desempenhar atividades, tentando explicar o porquê das implicâncias. Sua mulher é "picuinha" com ele porque é demasiadamente cuidadosa, meticulosa e detalhista. Em outras palavras, ela implica porque quer tudo ao seu modo, e ainda que isso represente uma qualidade, provoca desconfortos. Castanheira por vezes se desestimula para tarefas do cotidiano, que perdem o sentido quando se exige que sejam performadas de maneira perfeita (na maior parte das vezes, necessitam ainda de uma revisão). Ele se sente desconsiderado em seu esforço. Está mostrando, portanto, algo que acontece mediante toda essa reconfiguração: uma desmotivação ou desestimulação. Nota-se um realce dos problemas, claramente entendido como elemento do convívio e com nuances incidindo na qualidade dele (as diferenças entre ele e a esposa são percebidas como "baque"). Isto é, Castanheira está mais sensível a aspectos não antes captados.

Se as presenças confrontam o próprio casal, infere-se que a permanência supõe a tolerância e a negociação frente a essas exigências e cobranças que aparecem, senão às diferenças, desconfortavelmente acentuadas pelo convívio. O policial Castanheira mostra isso de forma simples e clara. Em sua história, tolerância e negociação despontam como imperativos, mas podem se anunciar de jeitos diferentes. Ele prossegue: "Isso também, (...) causa (ênfase) um certo desconforto entre os dois. Você quer até falar alguma coisa... mas você não quer magoar ela também. Aí, você deixa pra lá... mas, às vezes, você tem que dar aquela espetadinha.

Apreende-se a negociação mencionada anteriormente e um tipo de cuidado: renunciar ao desejo da crítica e ponderar o ímpeto são artimanhas para não magoar. Portanto, identifica-se uma estratégia desenvolvida para manter um bom funcionamento ou para assegurar a manutenção da relação, ainda que, às vezes, tenha que ser dada "aquela espetadinha".

Em uma mudança brusca na narrativa, Castanheira apresenta um esboço de uma história que, como todas as outras, deveria ser apenas mais uma em que ele se envolve emocionalmente com quem se relaciona. E ele tem justificativas para convencer que esse envolvimento seria como outro qualquer, pois como pessoa é cuidadoso e solícito, além de sensível. No entanto, foi diferente: a descrição não diz do envolvimento com a mulher com a qual permanece por 33 anos, mas sim de um acontecimento em que o objeto de amor foi uma cidadã que havia cometido um crime. O policial sublinha o que lhe atraiu: a sensação de ser valorizado, pois ele tentava prestar uma ajuda e a pessoa estava "reconhecendo isso", "sentindo isso". Ele explica:

Na época, eu estava tendo um... como diz o outro: um transtorno de relacionamento. (...) $E$ complicado, porque foi a única vez na minha vida que eu esqueci o que eu sentia pela minha mulher, talvez até igual eu falei, provocado pela situação geral né... e eu cheguei inclusive a falar assim, no tapa (bate com uma mão na outra): "infelizmente não dá mais, eu vou procurar outro relacionamento, até inclusive eu já estou envolvido, e não dá mais pra gente ficar junto". A minha mulher saiu de 62 pra 48 quilos... Você imagina o que ela sofreu... e calada.

O momento representou algo muito único. Ele afirma que essa foi a única vez em que esqueceu o que sentia pela mulher, "provocado" pela situação. Entende-se que, na fixação do amor-paixão - constatado na provocação que menciona - escapa a ponderação sobre o relacionamento com o qual tinha o compromisso conjugal, e ele se deixa absorver completamente pela outra mulher (ou é de alguma forma "capturado" pela conjuntura das ocorrências). O fato incontestável é o abalo experimentado pela relação, demonstrado tanto pelo sofrimento da esposa (que perdeu 14 quilos) quanto pela iniciativa momentânea de contar a ela sobre seu envolvimento com outra pessoa, em proposição do término do casamento.

Ele faz um relato detalhado de como foi o envolvimento - desde o momento em que se apaixo- 
nou, até as consequências que ele gerou. Ao assumir seu relacionamento extraconjugal, viveu as consequências em casa e no trabalho: o distanciamento da mulher, que estava em profunda amargura, e um processo no trabalho. Foi um "inferno", como cita Castanheira. No final das contas, foi livrado da acusação, mas a exposição dele e de sua esposa foi tremenda, pois tiveram que prestar contas para a polícia. A esposa foi "convidada" a depor e se surpreendeu ao saber a finalidade da intimação, mas reagiu de um modo inesperado, entrando em defesa do próprio marido, o qual se espantou.

A forma como o homem expõe a história, mediante gestos, tom de voz e explicação dos fatos, sugere grandiosa admiração pela esposa. Em meio a tanto sofrimento, em meio à dor e à sensação de ter sido enganada, ela foi capaz de defendê-lo e rogar a continuidade da relação. Observando a paixão em que se encontrava e confiando em seu amor, ela afirma sua posição. A partir disso, assimila-se a decisão de permanência através da confiança. No caso da esposa, ela confiava na índole de Castanheira, na pessoa dele e, além do mais, em seu sentimento por ele. Esses foram os fatores definitivos. O que sucedeu foi o seguinte:

Aquilo realmente, opa, acendeu uma luzinha, né. Aí realmente, e dali pra frente a gente nunca mais [falou do assunto]. A gente vê... eu noto que até hoje, mesmo passado muito tempo, (...) que ela vê uma cena de traição na novela, eu acho que ela remete o pensamento.

Ao vivenciar toda a situação, que envolveu tanto sofrimento, dor, mas também publicação de amor, desejo de prosseguir e vontade de superação por parte da esposa, Castanheira diz que "acendeu uma luzinha", "foi uma luz vermelha de pare" - gesticulou, apresentando a palma da mão. As marcas são inevitáveis e ele nos mostra como não existe "borracha" para apagar os eventos passados. No entanto, prevaleceu o projeto a dois com a esposa, ainda pressupondo reflexos do ocorrido, os quais são irremediáveis.

Recontou com detalhes sobre o seu envolvimento extraconjugal, compartilhando as minudências que configuraram sua história e sua experiência e mergulhou na busca de causas para explicar o ocorrido. A próxima transição, contudo, traz provocação e é excepcionalmente reveladora:

Eu acho que isso aí foi uma experiência... Não precisava ter havido, mas houve e... através dela, desse acontecimento, o nosso relacionamento melhorou mil por cento. A gente ficou mais chegado... (...). Até hoje a gente é como se fosse dois namorados. Tá parado os dois no sofá, vendo uma TV, cafuné, um carinho. Entendeu?

Os drásticos eventos que fizeram parte da vida de Castanheira e sua esposa, apesar de terem gerado tantos infortúnios, dores, sentimentos e mágoas, serviram incrivelmente para fortalecer a relação. $\mathrm{O}$ policial mostra que uma de suas principais queixas dos momentos ruins que a relação passou foi "extinta”, mediante os eventos dramáticos conectados ao relacionamento extraconjugal e às elaborações do casal. A relação deixou de ser fria e distante e os dois fazem mais questão de expressar afeições: "a gente ficou mais chegado... mais atenção um ao outro (...) Até hoje a gente é como se fosse dois namorados. (...) cafuné, um carinho". A adversidade é comparada a um estímulo que "despertou" o casal de um adormecimento afetivo. Castanheira avança:

Me arrependo muito... (...). Não só a exposição dela, mas o interno dela também, o interior. (...) Ela saiu de 62 e foi pra 48 quilos. É muito sofrimento para uma pessoa só. (...) Eu sentia que às vezes eu ia trabalhar e quando eu voltava ela tava com o olho inchado de chorar, quando eu chegava em casa. Entendeu? É... E a minha mulher, (...) não merecia, aí por isso meu arrependimento. Ela não merecia que eu deixasse acontecer isso que aconteceu. (...) Eu acho que ela tem o coração muito bom.

Não é difícil identificar, por inúmeras das falas, o cuidado que tem com sua esposa. Ele se considera imensamente o seu bem-estar. Portanto, a culpa se faz presente quando relembra o mal que causou a alguém de tamanha importância, demonstrando muita compaixão. Além do mais, "ficou uma ferida", e isso confirma o quanto o ocorrido ainda é atual na vida conjugal.

Neste momento, as memórias do percurso vêm à tona, pois a participação dela em sua vida profissional foi intensa. Novamente aflora o orgulho e fortalece a impressão de que há uma extraordinária importância atribuída à doação da mulher. Alguém que o ajudava no serviço, que se sujeitava a algumas situações por ele, por seu amor e companheirismo. E toda essa memória é visitada com muito carinho, com um gosto especial. Assim sendo, doação, companheirismo e compreensão são palavras substanciais na relação desse casal.

Todo o prazer identificável nessa rememoração traz o policial para um encontro com sua relação atualmente. Ele se vê satisfeito, ao observar sobressaírem os gestos afetivos, o cuidado, a proximidade. Talvez por receio de perder tais qualidades relacionais, ele projeta o futuro com esperanças da manutenção da relação, quando logo em seguida afirma: "Felizmente este resgate está sendo duradouro. Eu espero que não chegue naquele ponto que chegou, lá no passado da gente... Espero que não chegue nisso nunca mais".

Segundo ele, estar em relação duradoura tem a ver também com presenciar novidades constantemente. A convivência é uma progressão do aprendizado, algo que oferece oportunidades, inclusive de questionar a vida, os sentidos e as crenças:

O mais engraçado, Lucas, é o seguinte: por mais que você acha que conhece a pessoa, 
sempre tem uma novidade, e isso é que é o gostoso. (...) A gente já foi católico junto, a gente já foi umbandista quinze anos os dois juntos. (...) Hoje ela é evangélica e eu que já fui evangélico, hoje sou ateu.

O casal, junto, passou a se conhecer mais, desde os detalhes que advêm dos estímulos às presenças, até a companhia na descoberta e na afirmação das crenças. Tendo buscado juntos um contato com o transcendente, cada qual encontrou uma razão que culminou em um sistema distinto; entretanto, criou-se um novo desafio para o intenso contato e novos ajustes conjugais.

Na parte final da entrevista, sem se dar conta, ele retoma os assuntos do início, voltando às implicâncias presentes na convivência diária. Na concepção de Castanheira, o que o casal vive hoje é corolário de um processo natural do convívio de anos. Uma nova fase, um novo momento a se enfrentar, o qual carrega consigo as dificuldades peculiares a ele. Em certo ponto, ele diz que "isso é nossa prova de fogo", isto é, assume que é como se essa etapa fosse decisiva como provação para a vida conjugal. Ou seja, mais uma, entre várias outras já atravessadas. Há uma ideia de naturalidade subjacente ao seu discurso.

O conteúdo amoroso, entretanto, é irrefutável, saltando aos olhos em episódios alternantes, seja na tentativa do agrado, seja na disponibilidade de superar as dificuldades e os duros eventos do passado; seja na própria tolerância, ou no cuidado e no companheirismo. A entrevista é arrematada com a expressão deste último, identificado nos entremeios de seu desejo: quer se aventurar mais ainda com a esposa. Acampar e conhecer lugares. "Eu gosto de mostrar novidades para ela” representa a aspiração de introduzir-lhe o novo, mas, sobretudo, seu profundo anseio de vivenciar a vida com ela.

\section{Discussão dos resultados}

\section{A experiência do amor conjugal duradouro enquanto desprovida do romântico}

O elemento desromantizado dos relacionamentos amorosos conjugais duradouros possui algumas características próprias, que foram evidenciadas a partir da experiência dos entrevistados. A primeira delas é ser um acontecimento, isto é, o desromantizado é flagrado em seu lugar no duradouro assim como o próprio duradouro é percebido em uma relação conjugal amorosa, ou, antes, como o amor em si é percebido em um relacionamento conjugal. A tomada de consciência de que se está em uma relação duradoura sucede em um momento em que o duradouro já se encontra e que é uma configuração.

Ponderação e reflexão estão envolvidas nos relacionamentos, mas o aspecto de "acontecimento" diz respeito ao encontro com uma objetividade presente, isto é, o espaço em que as experiências subjetivas se dão. Esta consideração demonstra que as essências estão para além da estrutura da pessoa, pois se localizam em uma realidade em que a pessoa se situa.

A segunda compreensão possível do desromantizado se conecta à sua natureza de indeterminação e incerteza. Albertoni (2011) afirma que "basta estar em contato para que as pessoas sofram influências diretas em seus campos experienciais” (p. 89), o que intensifica a torrente natural de eventos inesperados. Isto nega a possibilidade dos relacionamentos se etiquetarem incólumes de influências, ou principalmente daquelas que são efetivamente problemas. O real incide, balança e abala. Assim acontece naturalmente.

Tomar os relacionamentos enquanto enquadres na ilusão do controle parece ser contrário ao duradouro. Na ciência de que há uma espontaneidade de afetações corriqueiras e de que as paixões no âmbito da psique são incontroláveis, assim como são os eventos ordinários pertencentes à esfera do cotidiano e do real, se reconhece que os relacionamentos amorosos conjugais duradouros não são providos de garantias tranquilizadoras. Exatamente por essa razão, escala-se o potencial de duradouro pela disponibilidade de aprofundamento na indeterminação e incerteza com o outro.

No caso da primeira entrevistada, o relato provoca a impressão de um funcionamento preservador de uma estabilidade e gera um palpite de que a relação está se regando do controle contra qualquer tipo de intercorrência. A análise do trecho irá revelar, contudo, que Maria Rita e seu Emanuel agem com naturalidade e espontaneidade em seus momentos de discórdia e intrigas, que não enunciam vigilância ou monitoramento de seus passos. Ao invés disso, o convívio, em sua sabedoria, produziu um movimento interacional leve no desempenho da conjugalidade. O mais evidente é sua aceitação quanto à intransigência das vicissitudes, que soam tão fluidas em sua narrativa como os câmbios da sombra diante do deslocamento do sol.

Os entrevistados demonstram como é prosaico e habitual ter a relação conduzida por curvas às vezes oblíquas, que prontamente movem a relação para direções malquistas e destituem o lugar de tranquilidade, exigindo adaptabilidade e resiliência extraordinárias. O "jogo de cintura" e a maleabilidade são básicos enquanto instrumentos de permanência.

Vislumbrando a incerteza e a indeterminação do amor, de uma forma geral, encontra-se a ausência de receitas e de fórmulas para a sua durabilidade. Se a ideia ou o desejo era decorar o futuro mediante o sentimento presente, o abismo que está entre o agora e o depois imprime a realidade da conjugalidade: é impossível preparar o conto de fadas feliz dos anos conseguintes, indefinidos e à mercê de variáveis e fatores indomesticados.

O terceiro e último ponto a ser destacado é o desromantizado enquanto desidealizado e medíocre. A fantasia é algo infalivelmente presente, pois há o desejo máximo de realização. Por este motivo, 
haverá esforços desmedidos no desenho de um projeto ideal. No entanto, quanto mais incide o tempo, menos capricho imaginativo de irrealidades e mais doses de verdades. Isso é uma rasteira no desejo de perfeição incitado pela idealização - uma desromantização que assola as partes. De acordo com a contribuição de Rogers (1976), pode-se inferir que a fantasia de uma relação sem conflito está fora de parâmetros reais e assim fadada ao fracasso, pois os relacionamentos são construções que exigem trabalho e até mesmo malabarismo para serem mantidos.

Com ou sem rodeios, a centralidade das narrativas se volta para uma simplicidade e uma mediocridade corriqueiras, em que não se pleiteia ou brota um feitiço realizador eterno. Polyanna, a segunda entrevistada, até expõe como foi presenteada inicialmente em sua relação pelo "pó do encantamento", cujo propósito era sinalizar-lhe seu destino com a parceira. Plausível e indubitável, até porque a experiência é uma realidade a trazer consigo uma verdade, mas há de se convir que a "polinização" não foi suficiente para garantir a fecundidade da permanência do encanto, já que ambas passaram por graves dilemas e sofrimentos. Mais clara é a experiência do policial quando conta que sua relação implicou exposição, perdas, julgamentos em uma situação específica, mas que também traz provocações e desentendimentos cotidianos.

Embora a visão de um amor desromantizado se mostre, não tem como intenção sugerir desesperança no amor e nos relacionamentos, cujos atrativos, prazeres e realizações são claros. Porém, desperta a crítica e o olhar para o real da relação, que é alheio à opulência arrogante do lirismo.

Se por algum momento pode trazer aversão com sua presença, o amor desromantizado é antagonicamente aquele que defere a durabilidade, pois permanece a relação que o suporta e que com ele dialoga. Os depoimentos trazem as marcas de sofrimentos que parecem fazer parte da longevidade. Frankl (1977/2015) declara que o núcleo da discussão não deve estar no sofrimento em si ou no prazer, mas no posicionamento frente a ele(s) e, embora afirme repetidas vezes que há produções de sentido que podem ser feitas sem sofrimento, em algum trecho de suas ponderações, deixa dúvida quanto à probabilidade de que ele seja evitado. ${ }^{6}$

A conjugalidade pode passar por ritos luxuriantes ou cerimônias solenes, por ostentações suntuosas ou pelo avassalamento designado pela paixão. No entanto, a posteriori não se prestará tanto a juramentos e se estabelecerá em convívio modesto. Tal forma de realização visa ao compartilhar, e ele se dilui nas pequenas causas e coisas da costumeira rotina. É definitivamente desromantizado porque sai de um plano especialíssimo para se tornar, de um modo, igual aos outros, medíocre.

\footnotetext{
6 "O sentido é possível mesmo a despeito do sofrimento - desde que, naturalmente, o sofrimento seja inevitável. Se ele fosse evitável, no entanto, a coisa significativa a fazer seria eliminar sua causa, fosse ela psicológica, biológica ou política". (Frankl, 2015, p. 138). A palavra grifada pelo próprio autor cria o problema: "se ele fosse"é porque não é?
}

\section{A experiência do amor conjugal duradouro enquanto abertura}

A abertura enseja os potenciais que o durar exige: é apenas mediante sua ingerência que se converte possível a experiência das adversidades que envolvem extremos e convidam a experimentações contrastantes: prazer e desprazer, alegria e sofrimento, altos e baixos, no inconstante leva e traz que a dinâmica pendular da vida incute. A abertura se mostrou tanto como decisão de permanência como acontecimento do duradouro.

Do campo de uma psicologia perceptual, como localiza Saint-Arnaud (1984), há um primado da subjetividade pelo qual se caminha na direção do entendimento da pessoa humana. Isso não escapole de um prisma fenomenológico em que se lida com a realidade enquanto percebida por alguém. Tomando neste momento o referencial subjetivo, rema-se para a área das decisões que definem a permanência em relacionamentos amorosos conjugais duradouros.

A relação se mantém quando cada uma das partes resolve permanecer, quando cada uma decide investir e trabalhar na manutenção do projeto. Arrebatados pelo cotidiano, por eventos dramáticos ou catastróficos (não importa de que ordem), os envolvidos podem ser provocados a um confronto com o outro e consigo mesmos, e o posicionamento será obrigatório: ele é uma exigência da realidade. Neste ponto, as contribuições de Ales Bello (2004, 2006) ajudam a compreender o registro ético do espírito na tomada de decisões, pois é justamente o espaço subjetivo que cuida das ressonâncias do psíquico. No caso dos entrevistados, houve a afirmação da continuidade apesar dos intempéries.

A história de Castanheira mostrou bem como o momento de traição convocou as presenças para se ocuparem de seus destinos, pois a esposa esteve diante do dilema de romper a relação ou não, considerando-se a infidelidade e, por consequência, dor e exposição foram experimentadas. Com Polyanna não foi diferente. Diante das circunstâncias, houve a necessidade de reafirmação do programa conjugal: renunciar ou não aos prazeres do corpo? Nada mais difícil que realizar esta escolha que, de maneira geral, envolvia necessariamente uma renúncia. Resta apenas aceitar e reconhecer que "fica uma (...) saudade" do que já foi vivido e de algo diferente da configuração recém estabelecida com estas privações.

Muitas vezes, as pessoas extraem sentidos diversos que estimulam as novas decisões de continuidade de forma fluida. Embora a narrativa de Maria Rita expresse uma naturalidade convincente de desdobramentos que sucederam em sua vida conjugal, não é por este motivo que se pode assumir um enfraquecimento de decisões. Sua ética subjaz cada momento onde se porta ao lado de Seu Emanuel para seguir enfrentando as adversidades. Do ponto de vista da subjetividade, é notório como o aspecto "abertura como decisão" se faz presente todo o tempo. Peter (2005) alerta que não deve haver qualquer sinal de espanto ao se falar de "de- 
cisão de amor”, simplesmente pelo fato de que é possível. A decisão é então um ato não instintivo e voltado ao sentido.

Já a abertura como acontecimento do duradouro aponta para uma verdade para além da decisão da pessoa. Sim, pois o decidir ocorre em um plano que é igualmente abertura antecipada à decisão de permanência nos relacionamentos. O duradouro aponta para o abrir-se ao amor (e, em consequência, ao continuar amando), neste movimento que é criatividade e geração.

Em todos os depoimentos, observou-se um tipo de cadência de acontecimentos que destaparam um mistério de permanência. Deparar-se com o duradouro é compreender que aquela relação só permaneceu por via de uma brecha para o porvir. Peter (2005), recorrendo às ideias de Viktor Frankl, diz que o homem é transcendente, ou seja, dirige-se ao mundo, sendo este um espaço denso de seres e de significados a serem realizados. Sem explicar a durabilidade dos relacionamentos, os entrevistados expõem as histórias e a continuidade dos mesmos como fatos brutos, tomando-as como este espaço de realização possível.

Mahfoud (2012) chama atenção para o ponto imprescindível da espera, que também se configura como abertura. Articula o sentido com a expectativa de uma correspondência de algo que valha a pena e que seja realizador. Seu ponto de vista fica mais claro quando fala de como isso acontece a partir do contato com outra pessoa: promessas e expectativas são geradas e significam, por si só, uma experiência de abertura que é realização. No entanto, a realização não está apenas no cumprimento das promessas, mas também na "experiência de abertura, concreta, ainda que limitada” (p.211), que abre espaço para possibilidades de realização sempre maiores.

Neste sentido, ainda que em todos os depoimentos seja possível identificar uma espera de possibilidades em um horizonte futuro, também são exibidas as evidências de uma realização constante. O policial Castanheira se lamuria a respeito das picuinhas da relação, porém, declara, em alusão às realizações que são cotidianamente presentes, que "sempre tem uma novidade, e isso é que é o gostoso". Além disto, as promessas e os anseios são concomitantes: "eu gosto de mostrar novidades para ela".

Buber (1923/2015) usa o termo "relação dialógica” para designar a qualidade da relação que é totalidade e fundamento da existência do homem. Este autor apresenta sua noção de outro enquanto aquele que não se reduz a um mero objeto. Essa experiência estruturante se concretiza na confirmação mútua entre dois parceiros através de abertura. Von Zuben (1981) reafirma o "entre" colocado por Buber enquanto o local mais importante da relação, no qual acontecem os eventos autenticamente humanos. Sobre o amor, Buber (1923/2015) profere: "o amor acontece (...) Não está ligado ao Eu de tal modo que o Tu fosse considerado um conteúdo, um objeto: ele se realiza, entre o Eu e o Tu”. (p. 59).

O amor, nesse ponto de vista, é um formador de vínculos e ultrapassa o sentimento, tornando- -se uma forma de fazer laços em uma experiência social que acontece e que representa uma abertura elementar.

\section{Considerações Finais}

Das unidades de sentido apreendidas com base nas experiências subjetivas presentes nos depoimentos, acompanhou-se o movimento de mostra do duradouro, que acabou por se situar entre os domínios do desromantizado e da abertura. Esse foi o ponto central do encontrado, por compreender os dois referidos elementos enquanto estruturantes da experiência investigada, classificada como experiência-tipo dos relacionamentos amorosos conjugais duradouros.

O desromantizado se destacou como resultante de uma série de condições sugestivas de uma experiência desprovida de determinação e certeza. Por outro lado, também se mostrou carente de idealização e importância sobrenatural, as quais são características que eventualmente fazem parte de relacionamentos em processo de adesão e engajamento. Ademais, seu caráter de acontecimento, que é prévio às decisões, também traz provocações acerca de seu mistério e de sua intransigência.

Com efeito, o desromantizado é definitivamente parte dessa experiência-tipo. Entretanto, coexiste e interage com a abertura que se sustenta enquanto decisão e acontecimento, na qual alguém a expressa em ação de posicionamento ou que, de repente, é vista como o algo que antes da decisão já funda as relações e o seu durar. É a abertura que coloca os seres diante do mistério vindouro. Enfim, o amor desromantizado e a abertura são os componentes mais essenciais da estrutura do relacionamento amoroso conjugal duradouro.

Por fim, em respeito ao tema, duradouro ou não, inexistem fórmulas e receitas para controlar o amor em sua essência. Esse desfecho de uma ideia também desromantizada não deve ser encarado como ultraje, mas sim enquanto a verdade mais simples, antiga e agora renovada sobre o fenômeno. Tampouco a abertura pode ser agarrada: ainda que exista a chance de voluntariamente abrir-se em operação de decisão, há uma mistura de responsabilidade com hesitação, por localizar-se também em meio a obscurantismos e ares nebulosos, demonstrando que há uma parcela de indeterminação e descontrole também sobre ela.

\section{Referências}

Albertoni, L. B. (2011). As atitudes transferenciais e a ACP. Revista do NUFEN, 3(1), 65-91.

Ales Bello, A. (2004). Fenomenologia e ciências humanas: psicologia, história e religião. Bauru: EDUSC.

Ales Bello, A. (2006). Introdução à Fenomenologia. Bauru: EDUSC. 
Amatuzzi, M. M. (1996). Apontamentos acerca da pesquisa fenomenológica. Estudos de Psicologia (Campinas), 13 (1), 5-10.

Amatuzzi, M. M. (2008). Por uma psicologia humana (2a. ed.). Campinas: Alínea.

Amatuzzi, M. M. (2009). Psicologia fenomenológica: uma aproximação teórica humanista. Estudos de Psicologia (Campinas), 26(1), 93-100.

Andrade, C. C., \& Holanda, A. F. (2010). Apontamentos sobre pesquisa qualitativa e pesquisa empírico-fenomenológica. Estudos de Psicologia. (Campinas), 27(2), 259-268.

Barreira, C. R. A., \& Ranieri, L. P. (2013).Aplicação de contribuições de Edith Stein à sistematização de pesquisa fenomenológica em psicologia: a entrevista como fonte de acesso às vivências. In M. Mahfoud\& M. Massimi (Eds.), Edith Stein e a psicologia: teoria e pesquisa (pp. 449-466). Belo Horizonte: Artesã.

Bauman, Z. (2004). Amor líquido: sobre a fragilidade dos laços humanos. Rio de Janeiro: Jorge Zahar.

Bauman, Z. (2007). Tempos líquidos. Rio de Janeiro: Zahar.

Bauman, Z. (2008). Vida para consumo: a transformação das pessoas em mercadorias. Rio de Janeiro: Zahar.

Buber, M. (2015). Eu e tu. São Paulo: Centauro.

Frankl, V. (2015). Em busca de sentido: um psicólogo no campo de concentração. São Leopoldo: Sinodal; Petrópolis: Vozes. (Trabalho original publicado em 1977)

Garnica, A. V. M. (1997). Algumas notas sobre pesquisa qualitativa e fenomenologia. Interface - Comunicação, Saúde eEducação, São Paulo, 1(1), 109-122.

Gaspar, Y. E., \& Mahfoud, M. (2010). Contribuições da fenomenologia para apreensão da articulação entre subjetividade e cultura: desafios e possibilidades. Anais do IV Seminário Internacional de Pesquisa e Estudos Qualitativos. Rio Claro: SE\&PQ.

Husserl, E. (2006a). Ideias para uma fenomenologia pura e para uma filosofia fenomenológica. Aparecida: Ideias \& Letras.

Lipovetsky, G. (1989). A era do vazio: ensaio sobre o individualismo contemporâneo. Lisboa: Relógio D’Água.

Lipovetsky, G. (2009). O império do efêmero: a moda e seu destino nas sociedades. São Paulo: Companhia das Letras.

Lipovetsky, G. (2004). Os tempos hipermodernos. São Paulo: Barcarolla..

Mahfoud, M. (2012). Experiência elementar em psicologia: aprendendo a reconhecer. Brasília: Universa; Belo Horizonte: Artesã.

Peter, R. (2005). Viktor Frankl: a antropologia como terapia. São Paulo: Paulus.
Rogers, C. R. (1976). Novas formas de amor: o casamento e suas alternativas. Rio de Janeiro: J. Olympio.

Saint-Arnaud, Y. (1984). A pessoa humana: introdução ao estudo da pessoa e das relações interpessoais. São Paulo: Edições Loyola.

Smith, J. A., \& Eatough, V. (2010). Análise Fenomenológica Interpretativa. In G. Breakwell, C. Fife-Schaw, S. Hammond, \& J. A. Smith (Orgs.), Métodos de pesquisa em Psicologia (pp. 322-339). Porto Alegre: Artmed.

Stein, E. (2003). Estructura da la persona humana. In E. Stein. Obras completas. Vol. IV: Escritos antropológicos y pedagógicos (pp. 555-749). Vitória: Ed. El Carmen; Madrid: Ed. De Espiritualidad; Burgos: Ed. Monte Carmelo.

Van der Leeuw, G. (1964). Fenomenología de la religión. (E. de la Peña, trad.) Fondo de cultura Económica. (Trabalho original publicado em 1933)

Von Zuben, N. A. (1981). O primado da presença e o diálogo em Martin Buber. Anais do Encontro Internacional de Filosofia da Linguagem. Campinas: CLE.

Lucas Baptista Albertoni: Psicólogo, Psicoterapeuta, Professor, Supervisor Clínico, Facilitador de Grupos e Palestrante. Possui mestrado em Psicologia (2016) e especialização Lato Sensu em Temas Filosóficos pela Universidade Federal de Minas Gerais (2013). Possui formação em Focusing (título de FocusingTrainer) pelo The FocusingInstitute, NY-EUA (2012) e em Psicoterapia Centrada no Cliente pelo Centro de Psicologia Humanista (2009). Possui graduação em Psicologia pela Pontifícia Universidade Católica de Minas Gerais (2007), com ênfase em Psicologia Clínica. Email: contato@lucasalbertoni.com

Sônia Regina Corrêa Lages: Professora Adjunta do Departamento de Ciência da Religião no Instituto de Ciências Humanas da Universidade Federal de Juiz de Fora. Graduada em Psicologia pela Universidade Federal de Juiz de Fora; Mestre em Ciência da Religião pela UFJF; Doutora em Psicossociologia de Comunidades e Ecologia Social pelo Departamento de Psicologia da UFRJ, e com Pós-doutorado na mesma área. Email: soniarclages@gmail.com

Recebido em 21.01.17

Primeira decisão editorial em 03.08.17

Aceito em 11.01.18 